\title{
Responses to Co-Workers Receiving Recognition at Work
}

Purpose: The purpose of this paper is to examine the impact of co-workers receiving recognition on two types of responses, namely emotions (positive and negative) and behavioral intentions (interpersonal counterproductive behavior and interpersonal citizenship behavior).

Design/methodology/approach: This study is an experimental scenario study with a $2 \times 2$ betweensubjects design with 246 employees from a local health care organization.

Findings: The findings reveal that the relation between other's recognition and positive or negative emotions was moderated by the quality of the relationship between both actors. Further, as hypothesized, the relation between other's recognition and interpersonal counterproductive behavior was moderated by relationship quality. Contrary to our expectations, relationship quality did not moderate the relation between employee recognition and interpersonal citizenship behavior.

Practical implications: This study provides useful suggestions for managers to diminish undesired (i.c., negative emotions and interpersonal counterproductive behavior) and enhance desired emotions and behaviors (i.c., positive emotions and interpersonal citizenship behavior).

Originality/value: This study is the first to show that employee recognition may have negative effects on other's emotions and interpersonal behavior (i.c., interpersonal counterproductive behavior).

Keywords: Employee recognition, relationship quality, interpersonal counterproductive behavior, organizational citizenship behaviors, positive and negative affect 


\section{Responses to Co-Workers Receiving Recognition at Work}

\section{Introduction}

In organizations, employee recognition is one of the motivational strategies that is gaining more and more attention and importance (e.g., Brun and Dugas, 2008; Long and Shields, 2010). Employee recognition is typically conceptualized as the assignment of personal non-monetary rewards to reinforce desired behaviors displayed by an employee, after these behaviors have occurred (Long and Shields, 2010; McAdams, 1999). Research concerning the effects of employee recognition shows promising results (e.g., Grawitch et al., 2006). As a result, at present both common sense and empirical evidence leads managers to conclude that recognition programs are highly effective motivational instruments.

However, before unambiguously recommending such strategies for enhancing employee morale, research should also examine potential negative side effects. The main focus of quantitative and qualitative reviews has been to examine the positive impact employee recognition has on task performance and other positive work-related outcomes (e.g., Greenberg and Ornstein, 1983; Stajkovic and Luthans, 1997, 2001, 2003). In contrast to this perspective, we argue that employee recognition might also have negative effects that have been largely overlooked. Within groups and organizations, employees might not only receive recognition themselves, but frequently witness others receiving recognition, be it directly (e.g., by observations) or indirectly (e.g., by stories). Thus, a crucial question to address is how the recognition given to others will impact on colleagues' responses.

In the present study, we examine the potential impact of others' recognition on one's own emotions and responses directed towards the individual, namely intentions to engage in interpersonal counterproductive behavior (CWB-I) and interpersonal citizenship behavior (OCB-I). Research has shown that these outcomes are crucial to organizations as they may have important and long-lasting effects on employees and the organization as a whole (e.g., Pearson and Porath, 2005; Podsakoff and MacKenzie, 1997).

On the basis of insights from social comparison theory, we expect relationship quality to determine when other-oriented recognition will lead to certain emotions (i.c., positive or negative affect) 
and to individually targeted behaviors (i.c., CWB-I and OCB-I). More specifically, by testing four moderation models we investigate how having a high or low quality relationship with the receiving person influences whether or not recognition will be associated with positive or negative affect, and with CWB-I and OCB-I. Thus, the theoretical contribution of our study to the literature on employee recognition is twofold: First, we document the understudied effects of recognition on co-workers' emotions and behavior. Second, we extend current knowledge by providing a better insight into the specific conditions (i.c., relationship quality) under which these responses will occur.

\section{Employee recognition}

For many years, there has been a debate about the role of monetary incentives in motivating employees (see Gerhart et al., 2009). Therefore, authors have recently called for searching alternative means of motivating employee behavior (Long and Shields, 2010). To meet the demands for more non-monetary incentives, scholars have introduced the concept of 'non-cash employee recognition' (e.g., Brun and Dugas, 2008). Empirical studies have consistently demonstrated that the use of employee recognition yields positive results in organizations, leading to an uncritical adoption of these practices in organizations (e.g., Stajkovic and Luthans, 2001, 2003). However, Long and Shields (2010) were among the first to challenge the dominant assumption in the literature, claiming that non-cash recognition programs are not at all problem free and may cause an atmosphere of 'winners' and 'losers'. However, to date their suggestion remains untested and currently the research on potential negative side effects is limited. This is unfortunate, as a good theoretical understanding of the effects of employee recognition involves a systematic test of all outcomes and their boundary conditions.

In the remainder we argue that witnessing co-workers receiving recognition may lead to positive emotions or negative emotions on the one hand, and to maladaptive interpersonal outcomes (i.c., CWB-I) and adaptive interpersonal outcomes (i.c., OCB-I) on the other hand. However, we argue that these responses will only occur under well-defined circumstances. More specifically, we expect that the quality 
of the relationship between the actors involved will moderate the relation between recognition and emotions, and between recognition and behavior.

\section{Relationship quality and emotions}

Research has shown that people tend to engage in friendships with people they perceive as being similar to them (Adams and Blieszner, 1994). High quality relationships at work are thus more likely to be characterized by similarity perceptions between co-workers. Hence, we expect that own responses to the treatment of a colleague might be influenced by these perceptions of (dis)similarity. According to social comparison theories, when people perceive themselves as being similar to another, they believe that they are able to attain the same status and rewards as the other person (Lockwood and Kunda, 1997). The process of comparing oneself to a similar other is called assimilation, and is usually accompanied by experiencing positive affect (Buunk et al., 2005). Hence, we expect that when one of two colleagues in a high quality relationship receives positive recognition, the other will feel good because the person believes (s)he might be able to gain the same recognition the friend/colleague has received in the future. In contrast, when one of both employees receives criticism, the other will experience negative emotions because this negative recognition could also apply to him/her.

The counterpart of the assimilation process is called a contrast effect, which emerges when someone perceives oneself as dissimilar to the other. The contrast effect generally leads to negative affect towards the person receiving praise or rewards (e.g., Ambrose et al., 1991). Hence, we expect that for colleagues in a low quality relationship receiving positive recognition, the observer will feel bad because (s)he believes (s)he might not be able to receive the same praise the colleague has received. In contrast, when such a co-worker receives criticism, the other will experience positive emotions because such a negative recognition suggests that the other is not better than him/her.

Although few studies have examined whether relationship quality between co-workers has an influence on their reactions at work, research has shown that relationship quality between an employer and employee is important for employee reactions to praise or criticism by the supervisor. One of the first 
studies investigating the quality of the relationship between supervisor and subordinate found that a highquality relationship between both parties was associated with more favorable reactions after praise or criticism, whereas a low-quality relationship was associated with unfavorable employee reactions (Snyder et al., 1984). In two studies, Feys et al. (2008) found that relationship quality moderated the relation between performance appraisal justice perceptions and employee reactions. Finally, a recent social relations analysis of peer ratings of performance shows that the interpersonal relationship component explained the most variance in performance ratings, more than the ratee or rater component (Greguras et al., 2007). These results suggest that when it comes to interpreting and reacting to co-workers' recognition for performance, the nature of the relationship is an important factor to consider. As positive and negative affect are considered to be possible antecedents for relevant work-related outcomes (e.g., job satisfaction, Fisher, 2002; self-reported job performance, Liu et al., 2010), we believe employee emotions may be a first important response to other-oriented recognition.

In sum, we expect relationship quality to moderate the relation between employee recognition and emotions. It is important to note that in this study, we examine affect as an emotional state (= affect), which refers to discrete emotions as reactions to some specific cause or event, such as recognition (Belschak and den Hartog, 2009), rather than as an emotional trait (= affectivity), which refers to more generalized and stable individual differences (Watson et al., 1988). We adopted this state approach because it is congruent with our manipulations in the scenarios used (for a similar approach, see Belschak and den Hartog, 2009). In line with this conceptualization, our operationalization of emotional state involved a measure that required participants to report their immediate reaction to the situation at hand. Thus, the hypotheses we propose are the following:

Hypothesis 1a: Relationship quality will moderate the relation between other-oriented recognition and positive affect: there will be a positive relation when relationship quality is high, and a negative relation when relationship quality is low. 
Hypothesis 1 b: Relationship quality will moderate the relation between other-oriented recognition and negative affect: there will be a positive relation when relationship quality is low, and a negative relation when relationship quality is high.

\section{Relationship quality and behavioral intentions}

\section{Interpersonal counterproductive behavior}

Over the years, the occurrence of counterproductive behavior has increased dramatically in organizations (O’Leary-Kelly et al.,1996). Overall counterproductive work behavior is commonly defined as 'any intentional behavior on the part of an organization member viewed by the organization as contrary to its legitimate interests' (e.g., Gruys and Sackett, 2003, pp. 30). On the basis of the target or referent of these behaviors, counterproductivity has further been categorized as being either interpersonally directed or organizationally directed (e.g., Robinson and Bennett, 1995). Interpersonally directed counterproductive behavior, which we will focus on in this study, involves behaviors that go against the legitimate interests of another individual in the organization, such as verbal or physical abuse or more passive acts (e.g., purposely failing to help a co-worker or doing work in an incorrect manner; Fox et al., 2001). Therefore, we believe CWB-I may be a first important behavioral response to other's recognition.

Research has shown that engaging in CWB-I is affected by social comparison. Lam et al. (2011) recently found that comparison to a higher performing team member was positively associated with CWBI. Moreover, studies have shown that when an employee's performance is compared to other's performance, the perceived identity threat that follows may trigger interpersonally harmful behavior (Aquino and Douglas, 2003). Most people strive to maintain positive self-identities (e.g., Bies, 1999; Brockner, 1988) and so they are highly motivated to defend themselves against acts that threaten these identities (e.g., Baumeister et al., 1996). The treatment a person receives from others is an important source of identity validation (e.g., Aquino and Douglas, 2003; Lind and Tyler, 1988). Consequently, when someone experiences mistreatment in any way by a co-worker or supervisor (for instance, by seeing a coworker one has a good relationship with receive criticism, or a co-worker one has a poor relationship with 
receive praise), this can lead to a perceived threat of one's personal identity (e.g., Bies, 1999; Lind and Tyler, 1988) which can provoke antisocial behavior towards other individuals (Aquino and Douglas, 2003). Similarly, Venkataramani and Dalal (2007) argue that interpersonal harming in organizations may be influenced by a lack of identification between co-workers. Because of the importance of interpersonal relationships between co-workers, researchers have consistently called for more studies to examine relational antecedents of such interpersonal counterproductive behaviors (e.g., Glomb and Liao, 2003; Venkataramani and Dalal, 2007). Thus, we expect the interaction between third-party recognition and relationship quality to lead to CWB-I. We therefore propose the following hypothesis:

Hypothesis 2: Relationship quality will moderate the relation between other-oriented recognition and interpersonal counterproductive behavior: There will be a positive relation when relationship quality is low, and a negative relation when relationship quality is high.

\section{Interpersonal citizenship behavior}

An early definition of overall organizational citizenship behavior describes this construct as: 'individual behavior that is discretionary, not directly or explicitly recognized by the formal reward system, and that in the aggregate promotes the effective functioning of the organization' (Organ, 1988, pp. 4). As for CWB, OCB can be categorized in interpersonally and organizationally directed behaviors. Interpersonally directed citizenship behavior involves behaviors directed at others in the organization that go beyond one's immediate role requirements (Venkataramani and Dalal, 2007) such as voluntarily helping coworkers to be more productive and providing interpersonal support (Bateman and Organ, 1983; Venkataramani and Dalal, 2007). Such behavior often has an affiliative-promotive character (Van Dyne and LePine, 1998), being grounded in friendship and social support (Settoon and Mossholder, 2002). In this study, we again focus on the interpersonal aspect of this outcome.

Spence et al. (2011) lament that until now virtually no research has been conducted to examine when employees engage in such helping behaviors. In their study, these authors found that social comparison between co-workers had an effect on OCB-I. Other research has also found support for the 
general quality of working relationships (between co-workers or between supervisor-subordinate) as predictors of employee helping behavior (e.g., Illies et al., 2007; Settoon and Mossholder, 2002; Venkataramani and Dalal, 2007). One reason for the relation between interpersonal relationships and OCB-I may be that high-quality relationships at work are characterized by empathy, leading a person to have a certain awareness of the personal and work-related needs of others (Settoon and Mossholder, 2002). When this other person then receives praise or criticism (which is a violation or confirmation of these needs), interpersonal citizenship behavior may be displayed. Because of the importance of OCB-I and because of the insufficiency of current psychological models to understand behaviors that occur primarily within the confines of interpersonal relationships (Korsgaard et al., 1997), researchers in the citizenship literature have called for more attention to relational antecedents of such behaviors (Venkataramani and Dalal, 2007). In sum, we expect the interaction between third-party recognition and relationship quality to lead to OCB-I. Thus, we propose the following hypothesis:

Hypothesis 3: Relationship quality will moderate the relation between other-oriented recognition and interpersonal citizenship behavior: There will be a positive relation when relationship quality is high, and a negative relation when relationship quality is low.

\section{Method}

\section{Participants}

Participants were administrative employees in a large Belgian health care organization ( $81 \%$ female). Their ages ranged from 21 to 62 years $(M=39, S D=11)$. An informal communication environment characterized the organizational culture with frequent interactions between different staff levels, both in vertical and horizontal direction. Before dispersing the questionnaires an informative meeting was held for all members of the administrative staff $(N=403)$. After the meeting, employees were able to fill out a questionnaire and put it in a box in a separate room. Participation was voluntary. Two hundred and fortysix employees filled out the questionnaire, yielding a response rate of $61 \%$. 


\section{Procedure}

The study was a 2 (positive versus negative recognition) x 2 (good versus poor relationship quality) between-subjects design. Four scenarios were developed reflecting the four experimental conditions. Participants were randomly assigned to one of the four conditions. An overview of descriptive statistics across all conditions can be found in Table 1. In using scenarios, we followed Belschak and den Hartog (2009) who also indirectly induced emotions by means of vignettes and Bui and Pelham (1999) who experimentally offered social comparison information directly to the participants in the study. The primary advantage of using scenarios is that they control internal validity and are more appropriate than other methods to test causal relations. Thus, participants filled out how they would react (i.c., their emotional responses and behavioral intentions) after such a situation would happen.

Instructions were as follows:

"Think about a specific person in your organization whom you frequently work with but you don't/do get along with. This colleague is never/always there for you and you have the feeling you can't/can trust him/her. You can't/can talk to this person about personal things, and you are not at all/are inclined to meet this person beyond working hours. The person you are thinking about receives praise/criticism from your supervisor. According to this supervisor, your colleague is doing an excellent/lousy job and (s)he is one of the best/worst performers in your department. Your supervisor is really pleased/not pleased at all about your colleagues' performance and is extremely satisfied/dissatisfied with him/her."

To minimize demand effects, we used a between-subjects design with participants rating only one scenario instead of a within-subjects design with participants rating all scenarios. Finally, respondents were asked to complete several questionnaires concerning work attitudes and work behaviors that were part of a larger survey.

Insert Table 1 here

\section{Measures}


Control measures. Studies indicate that men tend to be more aggressive and engage more in counterproductive behaviors than women (e.g., Fesbach, 1997). Further, the organizational literature (e.g., Geen, 1990) suggests that age is related to the incidence of workplace aggression, with younger employees engaging more in such unwanted behaviors. Therefore, we included gender and age as control variables in all analyses.

Positive and negative affect. Affective states were measured using the 12-item questionnaire by Belschak and den Hartog (2009). The instrument was used in its 'state' (short-term) form to assess affective experiences as an immediate reaction to a certain event, and not in its 'trait' (long-term) form, which would be used to assess a generalized individual difference. As described by Belschak and den Hartog (2009), combined positive emotions (positive affect) and negative emotions (negative affect) as a reaction to feedback equal the respondent's mean score on all measured positive or negative emotions after experiencing the scenario. Combining a score on specific emotions in overall positive/negative affect measures is often done in experimental research investigating the effects that emotional states have on behaviors (e.g., Raghunathan and Pham, 1999). For a similar scenario study approach, also see Belschak and den Hartog (2009). After reading the scenario, respondents got the following instructions: 'To what extent do you feel the following emotions towards X?'. Next, they rated the items on a 7-point Likert-type scale ranging from 1 (very weakly) to 7 (very strongly). Sample items are 'proud', and 'happy' for positive affect, and 'disappointed', and 'frustrated' for negative affect. Internal consistencies of the scales were .86 (positive affect) and .87 (negative affect).

Intentions to engage in CWB-I. Respondents completed 4 CWB-I items taken from Kelloway et al. (2002; items modified from Robinson and Bennett's list of workplace deviance behaviors, 1995) that represent CWB-I on a 5-point Likert-type scale ranging from 1 (totally disagree) to 5 (totally agree). Research has shown that these self-reports were significantly related to co-workers' reports of this scale $(r$ $=.46, p<.01$; De Jonge and Peeters, 2009). Further, self-reported CWB correlated with emotional job demands $(r=.31, p<.05)$ and co-worker reported CWB correlated with emotional resources $(r=-.31, p<$ .05) (De Jonge and Peeters, 2009). Upon reading the scenario and before filling out the questionnaire, 
respondents were asked: "I would be inclined to display the following behavior". A sample item is 'Spreading rumours about my colleagues'. Internal consistency of this scale was .86 .

Intentions to engage in OCB-I. Respondents completed the 6 items formulated by Konovsky and Organ (1996; altruism items originally developed by Smith et al., 1983) that represent OCB-I on the same 5-point Likert-type scale. Research has shown that this measure is significantly related to other forms of OCB-I (e.g., civic virtue, sportsmanship, courtesy and generalized compliance; $r$ between .21 and .63, $p<$ .01; Konovsky and Organ, 1996) and to desirable interpersonal behavior (e.g., supervisor ratings of employees' pro-social behavior; $r=.53, p<.01$; George, 1991). The same question as for CWB-I preceded this questionnaire. A sample item is 'Help others who have heavy work loads'. Internal consistency of this scale was .87 .

To date, OCB-I and CWB-I have been treated as separate constructs. Despite this, there are sufficient reasons to question whether construct and item overlap minimize the extent to which they are empirically separable (Kelloway et al., 2002). Therefore, we conducted confirmatory factor analysis in MPlus5 to examine the distinctiveness of CWB-I and OCB-I. In a first model both observed variables were posited to load on a single latent factor. Conceptually, this model does not distinguish between the two observed variables. The second model hypothesized two distinct yet correlated latent factors, wherein CWB-I was hypothesized to load on the first latent factor, and OCB-I was hypothesized to load on the second factor. Conceptually, this model distinguished between both dependent variables. The results of this analysis can be found in Table 2. The one-factor model showed no outstanding fit to the data. The two-factor model, however, fitted the data significantly better than the one-factor model, so we can conclude that both constructs were empirically distinct from each other.

Insert Table 2 here

\section{Results}


Correlations between study variables and descriptive statistics are presented in Table 3. In all analyses, we controlled for gender and age. To enhance interpretation, we centered predictor variables prior to computing cross-product terms (Aguinis, 2004; Aiken and West, 1991).

Insert Table 3 here

\section{Manipulation checks}

To test the effectiveness of both manipulations, respondents were asked 'How do you perceive the recognition given to the co-worker?' and 'How do you perceive the quality of the relationship between both co-workers?' on a 5-point Likert-type scale, with, respectively $1=$ Very negatively/poor and $5=$ Very positively/good. The effect of recognition on the first manipulation check was statistically significant, $F(1,238)=57.13, p<.001, \mathrm{y}^{2}=.20$. The mean ratings differed significantly from one another in the expected direction. The effect of relationship quality on the second manipulation check was also statistically significant, $F(1,239)=212.10, p<.001, \mathrm{y}^{2}=.47$. Again, mean ratings differed significantly from one another in the expected direction. Thus, the manipulation checks show that both manipulations had the desired effect.

\section{Hypotheses 1a and 1b}

To test Hypothesis 1a, we conducted a regression analysis to see which predictors, including the interaction term of relationship quality and recognition, had a statistically significant effect on positive affect. In order to obtain regression coefficients that are interpretable in a standardized metric, all predictors and the criterion variables were converted into standard scores before creating the product term (see Aguinis, 2004, pp. 38-39). Results are shown in Table 4 ( $1^{\text {st }}$ part). As hypothesized, the interaction between recognition and relationship quality was statistically significant $(R=.69, F(5,234)=41.89, p<$ .001). To determine if the pattern of the interaction was consistent with our hypothesis, we plotted the interaction in Figure 1. Standardized coefficients of the simple slopes were calculated by using the macros developed by O'Connor (1998). Both slopes were significantly different from zero $(p<.001)$. As 
predicted by Hypothesis 1a, Figure 1 reveals that there is a stronger positive relation between positive recognition and positive emotions when relationship quality is high, and a negative relation when this is low. In contrast, there is a positive relation between negative recognition and positive emotions when relationship quality is low, and a positive relation when this is high. Hypothesis 1a was thus supported.

Insert Figure 1 here

Next, we tested whether the interaction effect as proposed by Hypothesis $1 \mathrm{~b}$ had a statistically significant effect on negative affect. As can be seen in Table $4\left(2^{\text {nd }}\right.$ part $)$, this was indeed the case $(R=.66$, $F(5,234)=36.13, p<.001)$. Here as well, both slopes in Figure 2 were significantly different from zero $(p$ $<.001)$. Results are thus consistent with our predictions: there is a positive relation between positive recognition and negative emotions when relationship quality is low, and a negative relation when this is high. In contrast, there is a positive relation between negative recognition and negative emotions when relationship quality is high, and a positive relation when this is low. Thus, Hypothesis $1 \mathrm{~b}$ was supported.

Insert Table 4 and Figure 2 here

\section{Hypothesis 2}

To test Hypothesis 2, we again conducted a regression analysis. Here as well, all predictors and the criterion variables were converted into standard scores before creating the product term (see Aguinis, 2004, pp. 38-39). Results are shown in Table 5. As hypothesized, the interaction between recognition and relationship quality had a statistically significant effect on CWB-I $(R=.32, F(5,199)=4.51, p<.01)$. To determine if the pattern of the interaction was consistent with our hypothesis, we plotted the interaction in Figure 3. Standardized coefficients of the simple slopes were calculated by using the macros developed by O’Connor (1998). Both slopes were significantly different from zero $(p<.01)$. As predicted by Hypothesis 2, Figure 3 reveals that there is a stronger positive relation between negative recognition and CWB-I when relationship quality is high, and a negative relation when this is low. In contrast, there is a 
positive relation between positive recognition and CWB-I when relationship quality is low, and a negative relation when this is high. Hypothesis 2 was thus supported.

Insert Table 5 and Figure 3 here

\section{Hypothesis 3}

The same analysis as described for Hypotheses 1a, $1 \mathrm{~b}$ and 2 was conducted to test Hypothesis 3. Results are shown in Table 6. As can be seen in this table and in Figure 4, contrary to our expectations, the interaction between recognition and relationship quality did not have a statistically significant effect on OCB-I $(R=.24, F(5,204)=2.33, p>.05)$. Standardized coefficients of the simple slopes in Figure 4 were calculated by using the macros developed by O’Connor (1998). Both slopes were not significantly different from zero $(p>.05)$. Hypothesis 3 was thus not supported.

\section{Insert Table 6 and Figure 4 here}

\section{Discussion}

Taken together, the findings in this study point to potential negative side effects of employee recognition. First, we showed that emotional responses to other's recognition were a function of the relationship between both actors. Other's positive recognition led to the highest amount of negative emotions when the quality of the relationship was low, whereas the highest amount of positive emotions emerged when relationship quality was high. Second, our results show that harmful interpersonally targeted behaviors may result from employee recognition: Other's positive recognition led to the highest amount of CWB-I when the quality of the relationship was low, whereas the lowest amount of CWB-I was found when positive recognition was given to a liked co-worker. Finally, we did not find a moderating effect of relationship quality on the relation between employee recognition and OCB-I. One explanation is that recognition is mainly based on task outcomes and characteristics, which might not impact on helping behaviors towards others in the organization. In addition, it is important to note that there seems to be a 
notable difference between the strength of both manipulations (i.e., $\mathrm{y}^{2}$ values of .47 for the relationship quality manipulation and .20 for the recognition manipulation). This difference may explain the stronger effects for relationship quality compared to recognition. For instance, the results for Hypothesis $1 \mathrm{~b}$ summarized in Table 4 show that the coefficient for relationship quality is large (and statistically significant) whereas this is not the case for the coefficient for employee recognition. Hence, it is possible that this observed difference in manipulations strength may be (at least partly) responsible for the effect size of the obtained results in our study.

\section{Managerial and societal implications}

This study provides a number of implications for managers, organizations, and society. First, managers need to understand that recognition programs may not solely have the expected positive effects, and may even have negative effects on employees. This implies that managers and organizations should implement recognition programs as motivational strategies only under certain well-defined conditions. Although recognition might directly motivate the person receiving recognition, it might actually disturb co-workers' morale. Thus, it is important for managers and policy-makers to develop ways to limit such potential negative influences and increase the positive effects recognition may have. Second, managers should pay close attention to the setting in which they provide subordinates with praise or criticism. Managers should not give criticism when others are present, especially when the quality of the relationship between employees involved is high. We advise managers, when in doubt about the nature of this relation, to communicate recognition in private and to monitor informal communication for undesirable rumours. Third, the quality of the relationship between both colleagues seems a critical factor. Hence, it is crucial for organizations to plan interventions to improve relationships between colleagues, especially those that frequently interact. Companies can for instance stimulate activities amongst employees to increase mutual trust. The findings of this study also carry implications for society given that responses such as CWB-I pose a serious economic threat to organizations (e.g., Bennett and Robinson, 2000) and may have a tremendous negative impact on the effectiveness of individuals, work teams and organizations as a whole 
(Pearson and Porath, 2005), leading to high costs for organizations and society. Our study sheds a light on the possible antecedents of this outcome, and offers strategies to reduce these negative (i.c., CWB-I) outcomes.

\section{Limitations and suggestions for future research}

A first limitation applies to the use of scenarios that are often criticized for their lack of realism and potential demand effects. However, recent studies suggest that the use of scenarios in emotion research yields similar results, and that using scenarios in this particular context seems warranted (e.g., De Cremer and Van Knippenberg, 2004). Second, although a strength of the scenario design is the opportunity to draw causal conclusions about the role of the independent variables, the use of self-report measures for the moderator and the dependent variables introduces the threat of common method variance. In addition, we did not ask for reports of actual interpersonal counterproductive or citizenship behaviors, but rather of behavioral intentions. However, there is extensive research documenting the strong relation between intentions and behavior, much of it linked to the Theory of Reasoned Action (Fishbein and Ajzen, 1975), which posits intentions as the most direct precursor to behavior. Fourth, in the scenarios, employees were asked to think of a co-worker who always/never exhibits certain behaviors. It is clear that the actual behavior employees display tends to be more nuanced. Similarly, conditions in this study were worded such that high performers received praise and low performers received criticism. We are aware that in real work settings the possibility of a star performer receiving criticism or a mediocre performer receiving praise is also likely. However, we opted for simple and clear manipulations to ensure high internal validity. Future survey research in field studies should be conducted to strengthen the external validity of these findings, as the way in which recognition is given and the nature of relationships in organizations is typically more complicated than was depicted here. Further, future research could benefit from including motivation level and intent to quit in studies investigating the effects of employee recognition. It is possible that an employee's motivation level may increase sensitivity to the manipulations at hand, and hence impact on the emotions employees feel and behaviors they display. Finally, an interesting avenue 
for future research would be to examine how our findings generalize to other cultures. It becomes increasingly important to understand how cultural diversity in organizations relates to important workoutcomes. The findings of our study may be typical for more individualistic countries, but could be different when conducted in collectivistic countries (Hofstede, 1980). As individuals in collectivistic countries focus more on maintaining harmonious relationships with others and on achieving group goals rather than individual goals, it is likely that other-oriented recognition might lead to different emotions and work-outcomes in such cultures.

\section{Contribution and conclusion}

Our study contributes to the literature on employee recognition in three important ways. First, this study extends the effects of recognition on employee behavior by being the first to empirically challenge the dominant perspective that employee recognition has uniformly positive effects on work-related outcomes. We showed that, under specific conditions, employee recognition may have negative interpersonal (i.c., CWB-I) effects on other employees' responses and on other employees' positive and negative emotions. Second, our study adds to the literature by showing that recognition not only has an effect on emotions and work behaviors displayed by recognition recipients, but on those of 'bystanders' as well. Third, our study revealed that the quality of the relationship between two (or more) actors is crucial to understand why employees react to other's recognition in a particular way. The obtained findings thus call for caution when adopting employee recognition as a motivational strategy. We hope that the current findings are a first step in painting a more complete picture of the effects of employee recognition and will help to further develop it as a more effective motivational strategy for organizations. 


\section{References}

Adams, R. G. and Blieszner, R. (1994), “An integrative conceptual-framework for friendship research”, Journal of Social and Personal Relationship, Vol. 11 No. 2, pp. 163-184.

Aguinis, H. (2004), Regression Analysis for Categorical Moderators, Guilford, NY.

Aiken, L. S. and West, S. G. (1991), Multiple regression: Testing and interpreting interactions, Sage, Thousand Oaks, CA.

Ambrose, M. L., Harland, L. K. and Kulik, C. T. (1991), “Influence of social comparison on perceptions of organizational fairness", Journal of Applied Psychology, Vol. 76 No. 2, pp. 239-246.

Aquino, K. and Douglas, S. (2003), "Identity threat and antisocial behavior in organizations: The moderating effects of individual differences, aggressive modeling, and hierarchical status", Organizational Behavior and Human Decision Processes, Vol. 90 No. 1, pp. 195-208.

Bateman, T. S. and Organ, D. W. (1983), “Job satisfaction and the good soldier - The relationship between affect and employee citizenship”, Academy of Management Journal, Vol. 26 No. 4, pp. $587-595$.

Baumeister, R. F., Smart, L. and Boden, J. M. (1996), "Relation of threatened egotism to violence and aggression: The dark side of high self-esteem”, Psychological Review, Vol. 103 No. 1, pp. 5-33.

Belschak, F. D. and den Hartog, D. N. (2009), "Consequences of positive and negative feedback: The impact on emotions and extra-role behaviors", Applied Psychology: An International Review, Vol. 58 No. 2, pp. 274-303.

Bennett, R. J. and Robinson, S. L. (2000), “Development of a measure of workplace deviance”, Journal of Applied Psychology, Vol. 85 No. 3, pp. 349-360.

Bies, R. J. (1999), “Interactional (in)justice: The sacred and the profane”, in Greenberg, J. and Cropanzano, R. (Eds.), Advances in organizational behavior, The New Lexington Press, San Francisco. 
Brockner, J. (1988), “The effects of work layoffs on survivors: Research, theory, and practice”, in Staw, B. M. and Cummings, L. L. (Eds.), Research in organizational behavior, JAI Press, Greenwich, CT, pp. 213-255.

Brun, J-P. and Dugas, N. (2008), “An analysis of employee recognition: Perspectives on human resources practices", The International Journal of Human Resource Management, Vol. 19 No. 4, pp. 716 730.

Bui, K. V. and Pelham, B. W. (1999), “Cognitive and affective reactions to social comparison”, Journal of Social Behavior and Personality, Vol. 14 No. 4, pp. 569-583.

Buunk, B. P., Zurriaga, R., Peiro, J. M., Nauta, A. and Gosalvez, I. (2005), “Social comparisons at work as related to a cooperative social climate and to individual differences in social comparison orientation", Applied Psychology: An International Review, Vol. 54 No. 1, pp. 61-80.

De Cremer, D. and Van Knippenberg, D. (2004), "Leader self-sacrifice and leadership effectiveness: The moderating role of leader self-confidence", Organizational Behavior and Human Decision Processes, Vol. 95 No. 2, pp. 140-155.

De Jonge, J. and Peeters, M. C. W. (2009), "Convergence of self-reports and coworker reports of counterproductive work behavior: A cross-sectional muli-source survey among health care workers”, International Journal of Nursing Studies, Vol. 46 No. 5, pp. 699-707.

Feshbach, S. (1997), “The psychology of aggression: Insights and issues”, in Feshbach, S. and Zagrodzka, J. (Eds.), Aggression: Biological, Developmental, and Social Perspectives, Plenum, New York, pp. 213-235.

Feys, M., Libbrecht, N., Anseel, F. and Lievens, F. (2008), “A closer look at the relationship between justice perceptions and feedback reactions: The role of the quality of the relationship with the supervisor", Psychologica Belgica, Vol. 48 No. 2-3, pp. 127-156.

Fishbein, M. and Ajzen, I. (1975), Belief, Attitude, Intention, and Behavior: An Introduction to Theory and Research, Addison-Wesley, Reading, MA. 
Fisher, C. D. (2002), “Antecedents and consequences of real-time affective reactions at work”, Motivation and Emotion, Vol. 26 No. 1, pp. 3-30.

Fox, S., Spector, P. E. and Miles, D. (2001), "Counterproductive work behavior (CWB) in response to stressors and organizational justice: Some mediator and moderator tests for autonomy and emotions", Journal of Vocational Behavior, Vol. 59 No. 3, pp. 291-301.

Geen, R. G. (1990), Human Aggression, Brooks/Cole, Pacific Grove, CA.

George, J. M. (1991), "State or trait - Effects of positive moods on prosocial behaviors at work", Journal of Applied Psychology, Vol. 76 No. 2, pp. 299-307.

Gerhart, B., Rynes, S. L. and Fulmer, I. S. (2009), "Pay and performance: Individuals, groups, and executives", The Academy of Management Annals, Vol. 3, pp. 251-315.

Glomb, T. M. and Liao, H. (2003), "Interpersonal aggression in work groups: Social influence, reciprocal, and individual effects", Academy of Management Journal, Vol. 46 No. 4, pp. 486-496.

Grawitch, M., Gottschalk, M. and David, M. (2006), "The path to a healthy workplace: A critical review linking healthy workplace practices, employee well-being, and organizational improvements", Consulting Psychology Journal: Practice and Research, Vol. 58 No. 3, pp. 129-147.

Greenberg, J. and Ornstein, S. (1983), "High status job title as compensation for underpayment: A test of equity theory", Journal of Applied Psychology, Vol. 68 No. 2, pp. 285-297.

Greguras, G. J., Robie, C., Born, M. P. and Koenigs, R. J. (2007), “A social relations analysis of team performance ratings", International Journal of Selection and Assessment, Vol. 15 No. 4, pp. 434-448.

Gruys, M. L. and Sackett, P. R. (2003), “Investigating the dimensionality of counterproductive work behavior", International Journal of Selection and Assessment, Vol. 11 No. 1, pp. 30-42.

Hofstede, G. (1980), Culture's Consequences: International Differences in Work-Related Values, Thousand Oaks, CA, Sage.

Illies, R., Nahrgang, J. D. and Morgeson, F. P. (2007), “Leader-member exchange and citizenship behaviors: A meta-analysis”, Journal of Applied Psychology, Vol. 92 No. 4, pp. 269-277. 
Kelloway, E. K., Loughlin, C., Barling, J. and Nault, A. (2002), “Self-reported counterproductive behaviors and organizational citizenship behaviors: separate but related constructs", International Journal of Selection and Assessment, Vol. 10 No. 1-2, pp. 143-151.

Konovsky, M. A. and Organ, D. W. (1996), “Dispositional and contextual determinants of organizational citizenship behaviour", Journal of Organizational Behavior, Vol. 17 No. 3, pp. 253-266.

Korsgaard, M. A., Meglino, B. M. and Lester, S. W. (1997), “ Beyond helping: Do other-oriented values have broader implications in organizations?” Journal of Applied Psychology, Vol. 82 No. 1, pp. $160-177$.

Lam, C. K., Van der Vegt, G. S., Walter, F. and Huang, X. (2011), "Harming high performers: A social comparison perspective on interpersonal harming in work teams", Journal of Applied Psychology, Vol. 96 No.3, pp. 588-601.

Lind, E. A. and Tyler, T. R. (1988), The Social Psychology of Procedural Justice, Plenum, New York.

Liu, Y. M., Prati, L. M., Perrewe, P. L. and Brymer, R. A. (2010), "Individual differences in emotion regulation, emotional experiences at work, and work-related outcomes: A two-study investigation", Journal of Applied Social Psychology, Vol. 40 No. 6, pp. 1515-1538.

Lockwood, P. and Kunda, Z. (1997), "Superstars and me: Predicting the impact of role models on the self", Journal of Personality and Social Psychology, Vol. 73 No. 1, pp. 91-103.

Long, R. J. and Shields, J. L. (2010), “From pay to praise? Non-cash employee recognition in Canadian and Australian firms", The International Journal of Human Resource Management, Vol. 21 No. 8, pp. $1145-1172$.

McAdams, J. L. (1999), “Nonmonetary rewards: Cash equivalents and tangible awards”, in Berger, L. A. and Berger, D. R. (Eds.), The Compensation Handbook. A State-Of-The-Art Guide to Compensation Strategy and Design, McGraw-Hill, New York, pp. 241-260.

O’Connor, B. P. (1998), “SIMPLE: all-in-one programs for exploring interactions in moderated multiple regression", Educational and Psychological Measurement, Vol. 58 No. 5, pp. 836-840. 
O’Leary-Kelly, A. M., Griffin, R. W. and Glew, D. J. (1996), “Organization-motivated aggression: A research framework", Academy of Management Review, Vol. 21 No. 1, pp. 225-253.

Organ, D. W. (1988), Organizational Citizenship Behavior: The Good Soldier Syndrome, Lexington Books, Lexington, MA.

Pearson, C. M. and Porath, C. L. (2005), "On the nature, consequences and remedies of workplace incivility: Not time for “nice”? Think again", Academy of Management Executive, Vol. 19 No. 1, pp. 7-18.

Podsakoff, P. M. and MacKenzie, S. B. (1997), "Impact of organizational citizenship behavior on organizational performance: A review and suggestions for future research", Human Performance, Vol. 10 No. 2, pp. 133-151.

Raghunathan, R. and Pham, M. T. (1999), “All negative moods are not equal: Motivational influences of anxiety and sadness on decision making", Organizational Behavior and Human Decision Processes, Vol. 79 No. 1, pp. 56-77.

Robinson, S. L. and Bennett, R. J. (1995), “A typology of deviant workplace behaviors: A multidimensional scaling study", Academy of Management Journal, Vol. 38 No. 2, pp. 555572.

Settoon, R. P. and Mossholder, K. W. (2002), "Relationship quality and relationship context as antecedents of person- and task-focused interpersonal citizenship behavior", Journal of Applied Psychology, Vol. 87 No. 2, pp. 255-267.

Smith, C. A., Organ, D. W. and Near, J. P. (1983), “Organizational citizenship behavior: Its nature and antecedents", Journal of Applied Psychology, Vol. 68, No. 4, pp. 653-663.

Snyder, R. R., Williams, R. R., and Cashman, J. F. (1984), “Age, tenure, and work perceptions as predictors of reactions to performance feedback", Journal of Psychology, Vol. 116 No. 1, pp. 1121. 
Spence, J. R., Ferris, D. L., Brown, D. J. and Heller, D. (2011), “Understanding daily citizenship behaviors: A social comparison perspective", Journal of Organizational Behavior, Vol. 32 No. 4, pp. 547-571.

Stajkovic, A. and Luthans, F. (1997), “A meta-analysis of the effects of organizational behavior modification on task performance, 1975-95", Academy of Management Journal, Vol. 40 No. 5, pp. $1122-1149$.

Stajkovic, A. and Luthans, F. (2001), "Differential effects of incentive motivators on work performance", Academy of Management Journal, Vol. 44 No. 3, pp. 580-590.

Stajkovic, A. and Luthans, F. (2003), "Behavioral management and task performance in organizations: Conceptual background, meta-analysis, and test of alternative models", Personnel Psychology, Vol. 56 No. 1, pp. 155-194.

Van Dyne, L. and LePine, J. A. (1998), "Helping and voice extra-role behaviors: Evidence of construct and predictive validity", Academy of Management Journal, Vol. 41 No. 1, pp. 108-119.

Venkataramani, V. and Dalal, R. S. (2007), "Who helps and harms whom? Relational antecedents of interpersonal helping and harming in organizations", Journal of Applied Psychology, Vol. 92 No. 4, pp. 952-966.

Watson, D., Clark, L. A. and Tellegen, A. (1988), "Development and validation of brief measures of positive and negative affect: The PANAS scales", Journal of Personality and Social Psychology, Vol. 54 No. 6, pp. 1063-1070. 
Figure 1. Interaction of Employee Recognition and Relationship Quality on Positive Affect.

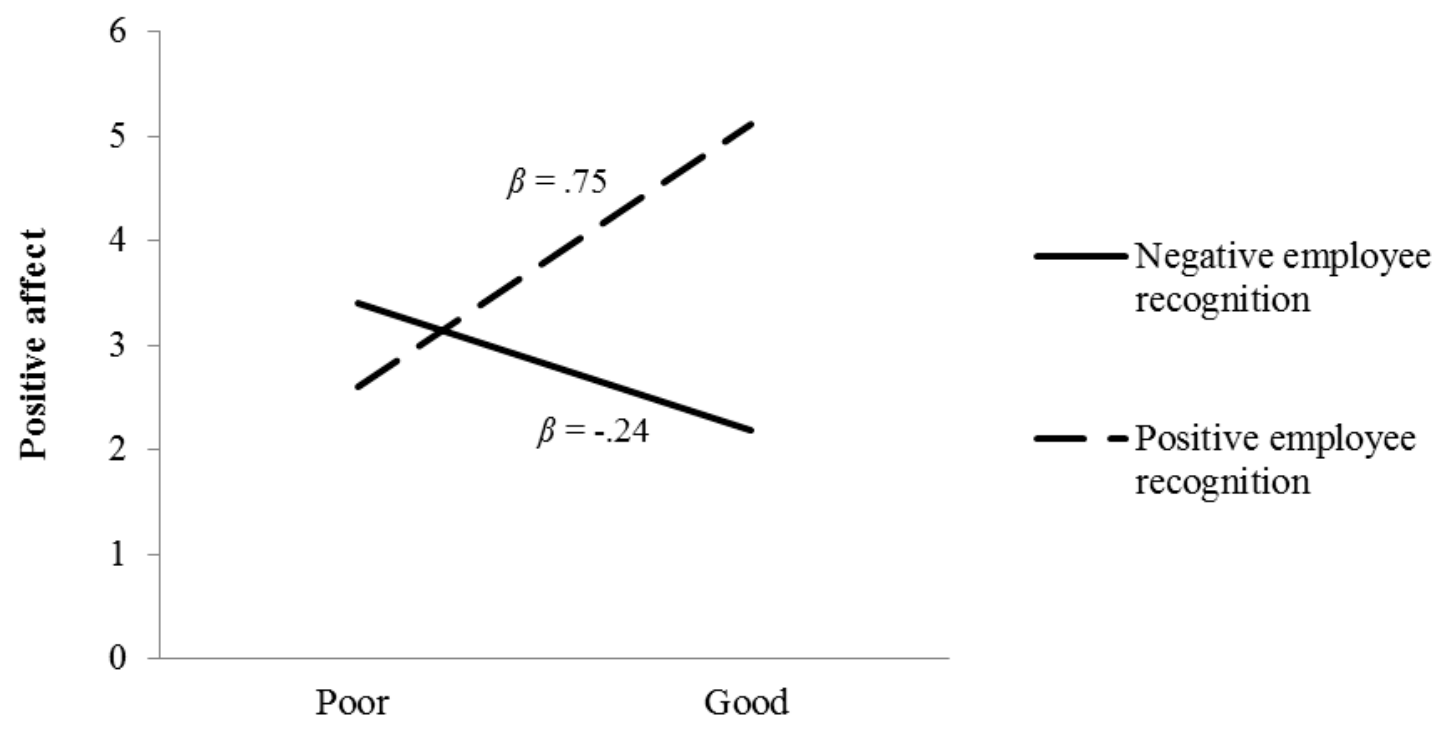

Relationship quality 
Figure 2. Interaction of Employee Recognition and Relationship Quality on Negative Affect.

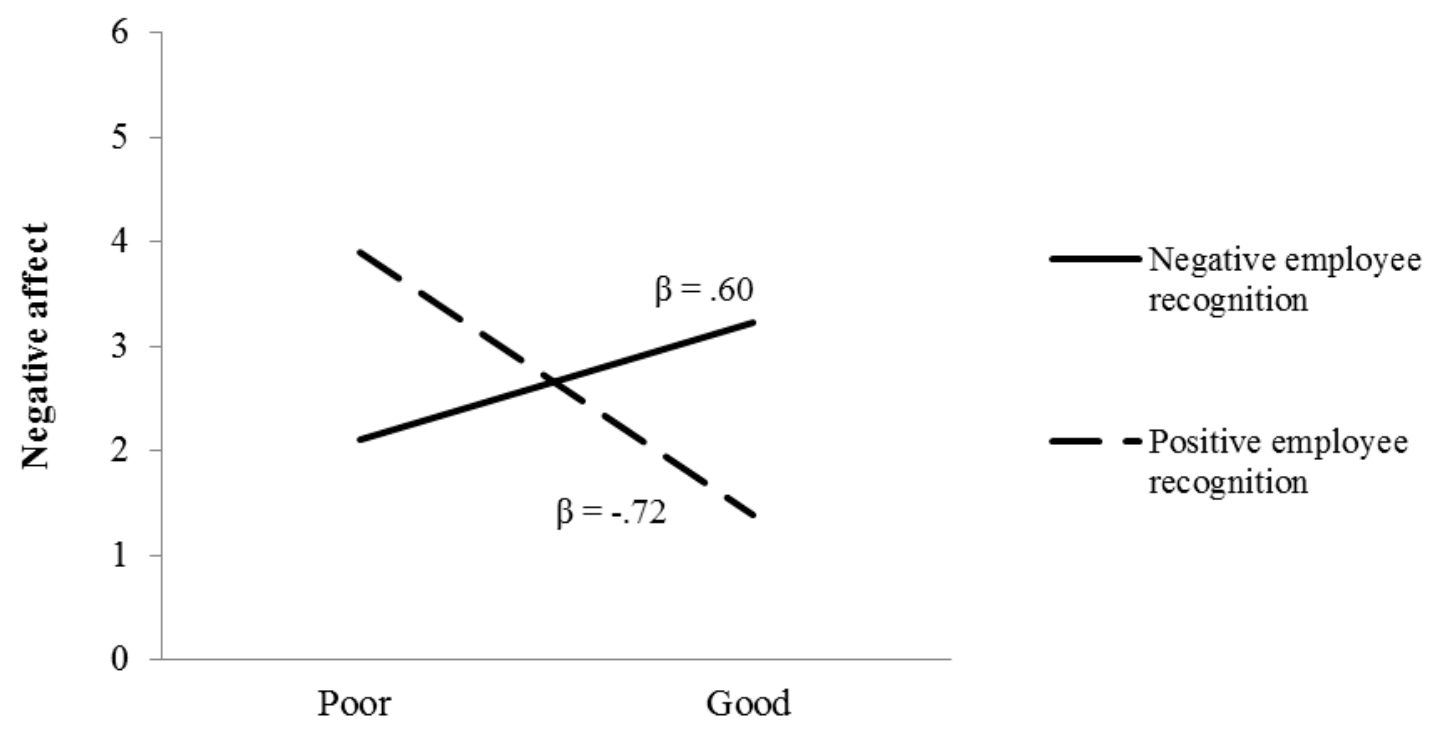

Relationship quality 
Figure 3. Interaction of Employee Recognition and Relationship Quality on Interpersonal

Counterproductive Behavior.

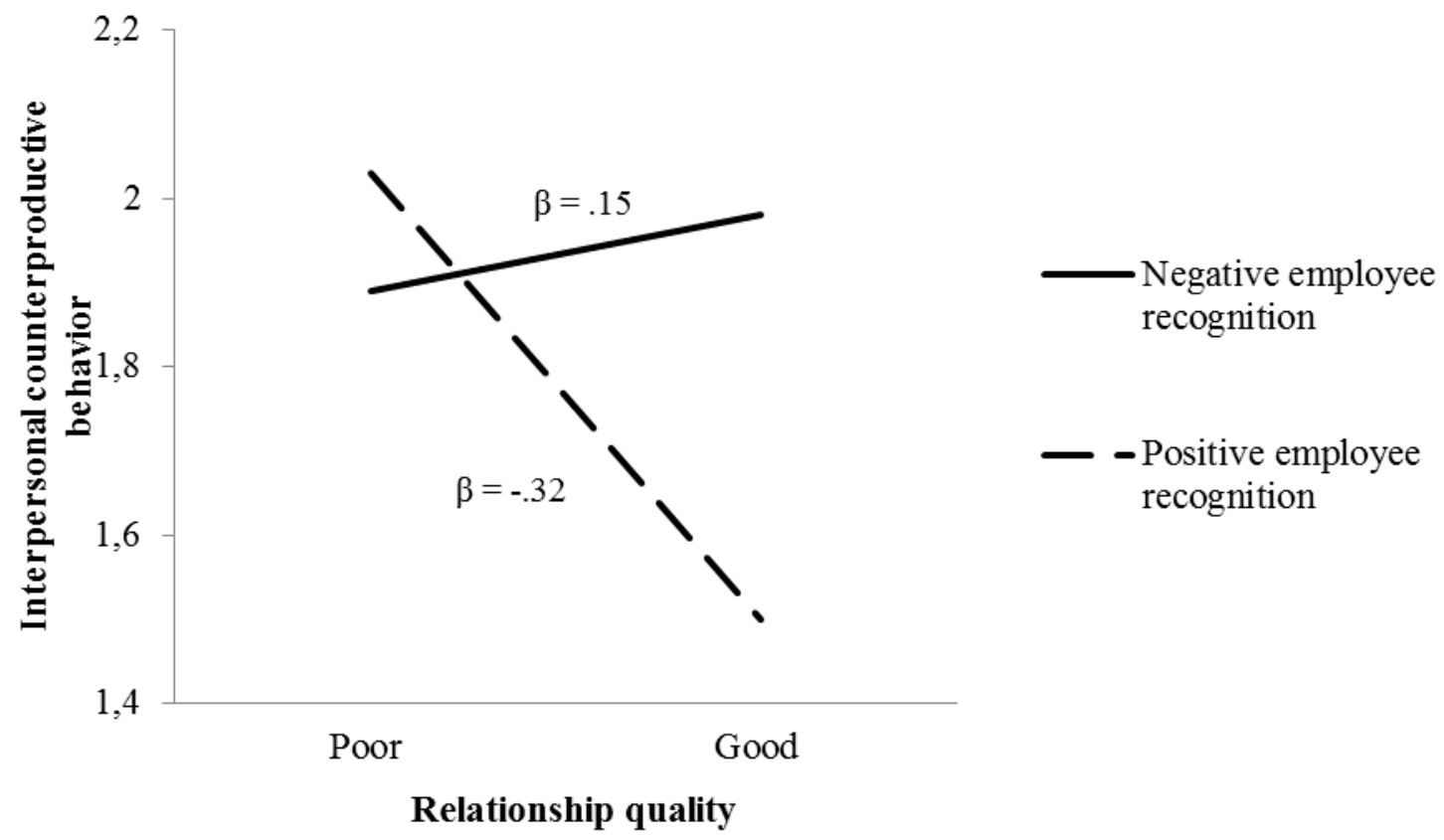


Figure 4. Interaction of Employee Recognition and Relationship Quality on Interpersonal Citizenship Behavior.

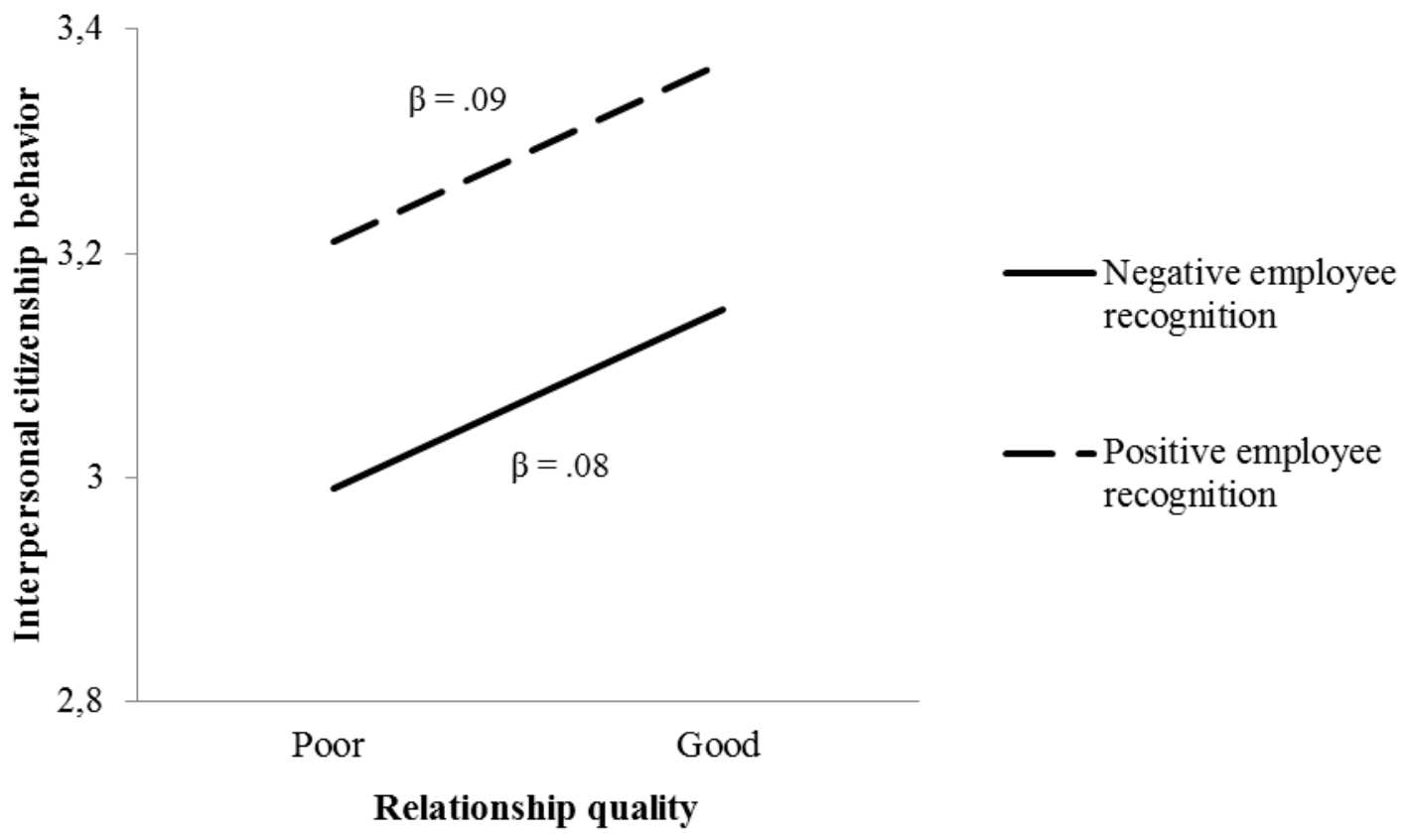


Table 1. Descriptive Statistics across Experimental Conditions.

\begin{tabular}{llllll}
\hline Scenarios & $N$ & $\begin{array}{l}\text { Positive } \\
\text { affect }\end{array}$ & $\begin{array}{l}\text { Negative } \\
\text { affect }\end{array}$ & $\begin{array}{l}\text { Interpersonal citizenship } \\
\text { behavior } \\
(M / S D)\end{array}$ & $\begin{array}{l}\text { Interpersonal counterproductive } \\
\text { behavior }\end{array}$ \\
\hline & $(M / S D)$ & $(M / S D)$ & $1 . S D)$ \\
\hline $\begin{array}{l}\text { Scenario 1 (High employee recognition, High } \\
\text { relationship quality) }\end{array}$ & 60 & $5.12(.99)$ & $1.38(.66)$ & $3.69(.74)$ & $1.45)$ \\
$\begin{array}{l}\text { Scenario 2 (Low employee recognition, High } \\
\text { relationship quality) }\end{array}$ & 62 & $2.18(1.16)$ & $3.23(1.13)$ & $3.87(.69)$ & $1.53(.66)$ \\
$\begin{array}{l}\text { Scenario 3 (High employee recognition, Low } \\
\text { relationship quality) }\end{array}$ & 58 & $2.59(1.27)$ & $3.94(1.64)$ & $3.54(.77)$ & $1.29(.44)$ \\
$\begin{array}{l}\text { Scenario 4 (Low employee recognition, Low } \\
\text { relationship quality) }\end{array}$ & 66 & $3.38(1.38)$ & $2.09(1.14)$ & $3.76(.66)$ \\
\hline
\end{tabular}


Table 2. Summary of Fit Statistics of Measurement Models Tested.

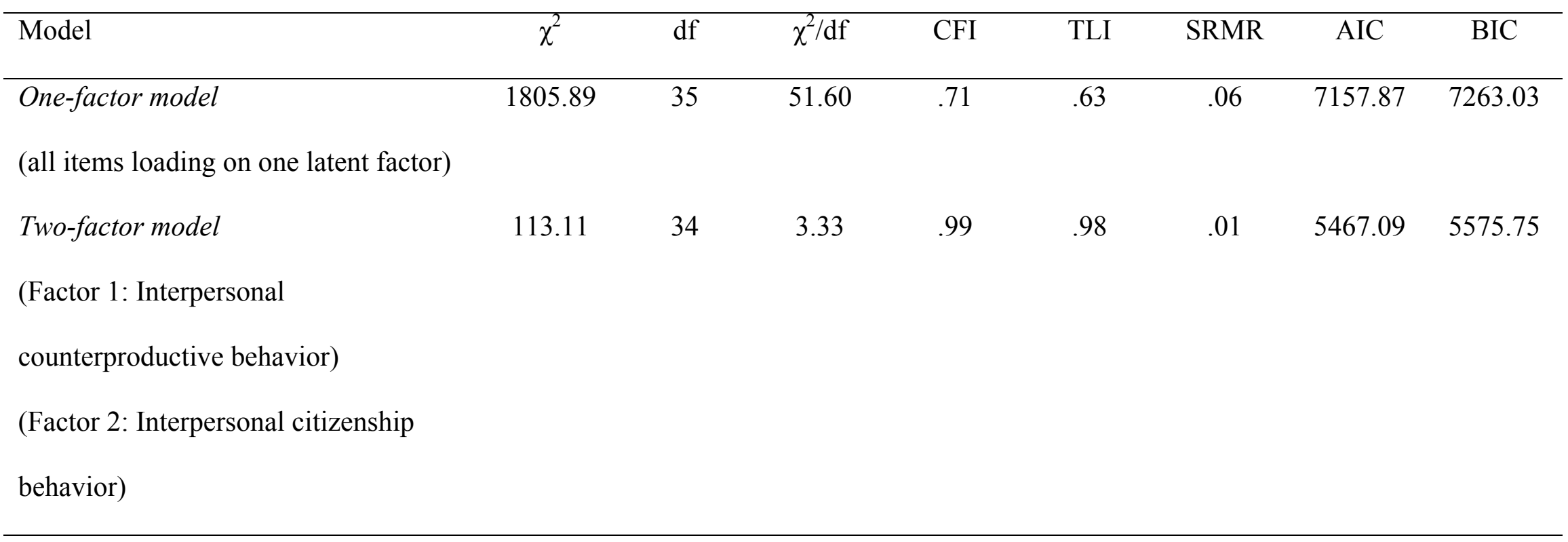

Note. $C F I=$ comparative fit index; $T L I=$ Tucker-Lewis index; $S R M R=$ standardized root mean square residual; $A I C=$ Akaike information criteria; $B I C=$ Bayesian information criteria. 
Table 3. Inter-correlations of Study Variables $(N=246)$.

\begin{tabular}{|c|c|c|c|c|c|c|c|c|c|c|}
\hline & $M$ & $S D$ & 1. & 2. & 3. & 4. & 5. & 6. & 7. & 8. \\
\hline \multicolumn{11}{|l|}{ 1. Gender ${ }^{a}$} \\
\hline 2. Age & 38.7 & 10.59 & $-.28 * *$ & & & & & & & \\
\hline 3. Employee recognition ${ }^{b}$ & .48 & .50 & .03 & -.03 & & & & & & \\
\hline 4. Relationship quality ${ }^{b}$ & .50 & .50 & $-.14^{*}$ & .03 & .02 & & & & & \\
\hline 5. Positive affect & 3.33 & 1.65 & -.07 & .02 & $.33^{* *}$ & $.20 * *$ & $(.86)$ & & & \\
\hline 6. Negative affect & 2.64 & 1.54 & -.02 & $-.21 * *$ & -.00 & $-.22 * *$ & $-.40 * *$ & $(.87)$ & & \\
\hline 7. Interpersonal citizenship behavior & 3.72 & .72 & .09 & .09 & $-.14^{*}$ & .09 & .02 & .01 & $(.86)$ & \\
\hline 8. Interpersonal counterproductive behavior & 1.37 & .55 & $-.16^{*}$ & -.14 & -.00 & -.05 & -.07 & $.30 * *$ & $-.17 *$ & $(.86)$ \\
\hline
\end{tabular}

Note. Internal consistency reliabilities are reported in parentheses on the diagonal.

${ }^{*} p<.05, * * p<.01$ (two-tailed)

${ }^{a}$ Gender was dummy coded, with $0=$ male and $1=$ female.

${ }^{\mathrm{b}}$ Manipulations in this study were dummy coded, with $0=$ poor relationship quality / negative recognition and $1=$ good relationship quality / positive recognition. 
Table 4. Summary of Regression Analysis on Positive Affect and Negative Affect $(N=246)$.

\begin{tabular}{|c|c|c|c|c|c|c|c|c|c|c|c|c|c|c|c|}
\hline & \multirow[b]{2}{*}{ Variable } & \multicolumn{6}{|c|}{ Positive affect (H1a) } & \multicolumn{8}{|c|}{ Negative affect (H1b) } \\
\hline & & $b$ & $S E(b)$ & $\beta$ & $t$ & $p$ & $R$ & $R^{2}$ & $b$ & $S E(b)$ & $\beta$ & $t$ & $p$ & $R$ & $R^{2}$ \\
\hline \multirow[t]{5}{*}{ Step 1} & Gender & -.27 & .21 & -.07 & -1.30 & .20 & $.69 * * *$ & $.47 * * *$ & -.37 & .20 & -.09 & -1.82 & .07 & $.66 * * *$ & $.44 * * *$ \\
\hline & Age & -.01 & .01 & -.06 & -1.22 & .23 & & & -.02 & .01 & -.16 & -3.07 & .00 & & \\
\hline & Employee recognition & 1.08 & .16 & .33 & 6.90 & .00 & & & -.01 & .15 & -.00 & -.07 & .95 & & \\
\hline & Relationship quality & .56 & .16 & .17 & 3.55 & .00 & & & -.67 & .15 & -.22 & -4.36 & .00 & & \\
\hline & $\begin{array}{l}\text { Employee recognition } \mathrm{x} \\
\text { Relationship quality }\end{array}$ & 3.78 & .32 & .58 & 12.02 & .00 & & & -3.58 & .31 & -.58 & $\begin{array}{l}- \\
11.76\end{array}$ & .00 & & \\
\hline
\end{tabular}

Note. $* * * p<.001$

$b$ are unstandardized coefficients; $\beta$ are standardized coefficients

$\beta$ are calculated by converting all predictors and criterion variables into standard scores, which are then used to compute the product term.

All predictor variables were centred prior to computing cross-product terms. 
Table 5. Summary of Regression Analysis on Interpersonal Counterproductive Behavior (N=246).

\begin{tabular}{|c|c|c|c|c|c|c|c|c|}
\hline & \multirow[b]{2}{*}{ Variable } & \multicolumn{6}{|c|}{ Interpersonal Counterproductive Behavior (H2) } & \multirow[b]{2}{*}{$R^{2}$} \\
\hline & & $b$ & $S E(b)$ & $\beta$ & $t$ & $p$ & $R$ & \\
\hline \multirow[t]{5}{*}{ Step 1} & Gender & -.32 & .10 & -.23 & -3.12 & .00 & $.32 * *$ & $.10 * *$ \\
\hline & Age & -.01 & .00 & -.17 & -2.41 & .02 & & \\
\hline & Employee recognition & .02 & .08 & .02 & .29 & .77 & & \\
\hline & Relationship quality & -.10 & .08 & -.09 & -1.24 & .22 & & \\
\hline & $\begin{array}{l}\text { Employee recognition } \mathrm{x} \\
\text { Relationship quality }\end{array}$ & -.42 & .15 & -.19 & -2.80 & .00 & & \\
\hline
\end{tabular}
Note. ${ }^{* *} p<.01$

$b$ are unstandardized coefficients; $\beta$ are standardized coefficients

$\beta$ are calculated by converting all predictors and criterion variables into standard scores, which are then used to compute the product term.

All predictor variables were centred prior to computing cross-product terms. 
Table 6. Summary of Regression Analysis on Interpersonal Citizenship Behavior $(N=246)$.

\begin{tabular}{|c|c|c|c|c|c|c|c|c|}
\hline & & & & terper & $\overline{\text { Citizer }}$ & Beha & & \\
\hline & Variable & $b$ & $S E(b)$ & $\beta$ & $t$ & $p$ & $R$ & $R^{2}$ \\
\hline Step 1 & Gender & .29 & .14 & .16 & 2.15 & .03 & .24 & .06 \\
\hline & Age & .01 & .01 & .12 & 1.63 & .10 & & \\
\hline & Employee recognition & -.21 & .10 & -.15 & -2.16 & .03 & & \\
\hline & Relationship quality & .16 & .10 & .11 & 1.59 & .11 & & \\
\hline & $\begin{array}{l}\text { Employee recognition } \mathrm{x} \\
\text { Relationship quality }\end{array}$ & -.00 & .20 & -.00 & -.01 & .99 & & \\
\hline
\end{tabular}

Note. $b$ are unstandardized coefficients; $\beta$ are standardized coefficients

$\beta$ are calculated by converting all predictors and criterion variables into standard scores, which are then used to compute the product term.

All predictor variables were centred prior to computing cross-product terms. 